\title{
UNMANNED AERIAL VEHICLE LASER SCANNING FOR EROSION MONITORING IN ALPINE GRASSLAND
}

\author{
A. Mayr ${ }^{1 *}$, M. Bremer ${ }^{2}$, M. Rutzinger ${ }^{2}$, C. Geitner ${ }^{1}$ \\ ${ }^{1}$ Institute of Geography, University of Innsbruck, Austria - (andreas.mayr, clemens.geitner)@ uibk.ac.at \\ ${ }^{2}$ Institute for Interdisciplinary Mountain Research, Austrian Academy of Sciences, Innsbruck, Austria - (magnus.bremer, mar- \\ tin.rutzinger)@oeaw.ac.at
}

Commission II, WG II/10

KEY WORDS: Topographic LiDAR, UAV, Accuracy, Change Detection, Object-based Analysis, Geomorphology

\begin{abstract}
:
With this contribution we assess the potential of unmanned aerial vehicle (UAV) based laser scanning for monitoring shallow erosion in Alpine grassland. A 3D point cloud has been acquired by unmanned aerial vehicle laser scanning (ULS) at a test site in the subalpine/alpine elevation zone of the Dolomites (South Tyrol, Italy). To assess its accuracy, this point cloud is compared with (i) differential global navigation satellite system (GNSS) reference measurements and (ii) a terrestrial laser scanning (TLS) point cloud. The ULS point cloud and an airborne laser scanning (ALS) point cloud are rasterized into digital surface models (DSMs) and, as a proof-of-concept for erosion quantification, we calculate the elevation difference between the ULS DSM from 2018 and the ALS DSM from 2010. For contiguous spatial objects of elevation change, the volumetric difference is calculated and a land cover class (bare earth, grassland, trees), derived from the ULS reflectance and RGB colour, is assigned to each change object. In this test, the accuracy and density of the ALS point cloud is mainly limiting the detection of geomorphological changes. Nevertheless, the plausibility of the results is confirmed by geomorphological interpretation and documentation in the field. A total eroded volume of $672 \mathrm{~m}^{3}$ is estimated for the test site (48 ha). Such volumetric estimates of erosion over multiple years are a key information for improving sustainable soil management. Based on this proof-of-concept and the accuracy analysis, we conclude that repeated ULS campaigns are a well-suited tool for erosion monitoring in Alpine grassland.
\end{abstract}

\section{INTRODUCTION}

Steep grassland in the montane to alpine elevation zone of the Alps is frequently affected by shallow erosion. Either shallow landslides or abrasion by snow gliding processes and full-depth avalanches initially displace the vegetation, soil and unconsolidated deposits (Wiegand and Geitner, 2010). This results in patches in the grassland without a vegetation cover, where surface runoff and wind can further erode material, usually up to a few decimetres depth (Fig. 1). While the size of these eroded areas (i.e. individual bare earth surface patches) typically ranges from only 2 to $200 \mathrm{~m}^{2}$, their large number in some regions (e.g. >30 areas per ha; Wiegand and Geitner, 2013) results in a considerable loss of soil and degradation of affected grassland (Tasser et al., 2005; Wiegand and Geitner, 2010; Alewell et al., 2015). As this also reduces the capability for slope water retention, negative impacts on hydrology and hydrological hazards can arise (Wiegand and Geitner, 2013). Therefore, the soil conservation protocol of the Alpine Convention, for instance, requests the monitoring and mitigation of soil erosion (CIPRA, 2005).

Shallow landslides (e.g. Ma et al., 2016) and grassland degradation (Wiesmair et al.; 2016) can be monitored with highresolution satellite imagery. Availability and cost often constrain the use of these (usually commercial) data products. Moreover, the spatial resolution is limiting the accurate mapping of shallow eroded areas, which are often smaller than $10 \mathrm{x}$
$20 \mathrm{~m}$ (Wiegand and Geitner, 2013). In this respect, data from airborne platforms has advantages in terms of spatial resolution. On the one hand, eroded areas (i.e. individual patches of bare earth in grassland) can be mapped from the spectral-spatial data of orthophotos in terms of their spatial extent, i.e. in 2D (Wiegand et al., 2013; Mayr et al., 2016). On the other hand, elevation changes due to various geomorphological processes can be derived from multi-temporal airborne laser scan (ALS) data (Baltsavias et al., 2001; Heritage and Large, 2009; Sailer et al., 2012; Jaboyedoff et al., 2012). Subtraction of raster digital elevation models (DEMs), derived from such topographic surveys, produce differential DEMs, also called DEMs-ofDifference (DoDs), which are commonly used to monitor geomorphic changes (Lane et al., 1994; Wheaton et al., 2010). To support semantic interpretations, surface classifications have exploited the laser intensity data (Syed et al., 2005; Höfle et al., 2007; Zlinszky et al., 2012). Zieher et al. (2016) visually interpreted a DoD, derived from multi-temporal ALS, in combination with aerial orthophotos to map shallow landslides with a minimum scar width of $10 \mathrm{~m}$.

For a more detailed geomorphological monitoring on a local scale, terrestrial (i.e. ground-based) topographic surveys, either by laser scanning or photogrammetric techniques, are frequently used (e.g. Vericat et al., 2014; Scaioni et al., 2015; Stumpf et al. 2015; Fey and Wichmann, 2017). The applicability, data extent, quality and completeness of terrestrial surveys can be strongly limited, depending on the local terrain conditions (such as

\footnotetext{
* Corresponding author
} 
accessibility and availability of scan or camera positions with sufficient visibility to the area-of-interest). In the last years, topographic surveys with unmanned aerial vehicles (UAVs) have strived to close the gap between (manned) aerial and terrestrial surveys for many applications. So far, UAV-based monitoring has mostly applied SfM-MVS (Structure-fromMotion and Multi-View Stereo) techniques (Eltner et al., 2016; Smith and Vericat, 2015). Recently, survey-grade systems for unmanned aerial vehicle laser scanning (ULS) have become commercially available (Shan and Toth, 2018). Until now, these ULS systems have been tested mainly for forestry applications, in specific for tree stem diameter estimation (Brede et al., 2017; Wieser et al., 2017).

For erosion monitoring, multi-temporal ULS is a promising method. Expected advantages include (i) a high spatial resolution and accuracy (compared to typical manned aerial surveys), (ii) coverage of larger areas with consistently high point density and accuracy (compared to typical terrestrial surveys), (iii) high accuracy with few or without ground control points (compared to photogrammetric techniques) and (iv) complementary provision of actively sensed signal intensity and co-registered colour images.

The goal of this contribution is to assess the potential of unmanned aerial vehicle laser scanning (ULS) to monitor shallow erosion in Alpine grassland. This includes two specific objectives:

(i) An accuracy assessment for the ULS point cloud using differential global navigation satellite system (GNSS) and terrestrial laser scanning (TLS) data as a reference.

(ii) A proof-of-concept for mapping and volumetric quantification of shallow erosion with ULS.
The presented study uses one ULS epoch to get a first evaluation of the potential of multi-temporal ULS campaigns for an erosion monitoring application before the upcoming field season (Fig. 2). Since a second ULS epoch is not yet available, an ALS epoch, acquired in 2010, is used as a substitute to develop and test an approach for raster-based mapping and volume quantification. To distinguish changes due to erosion and deposition from other changes (such as the removal of trees by humans or by avalanches), we combine geometric surface changes with semantic information derived from spectral features (Figs. 2 and 6).

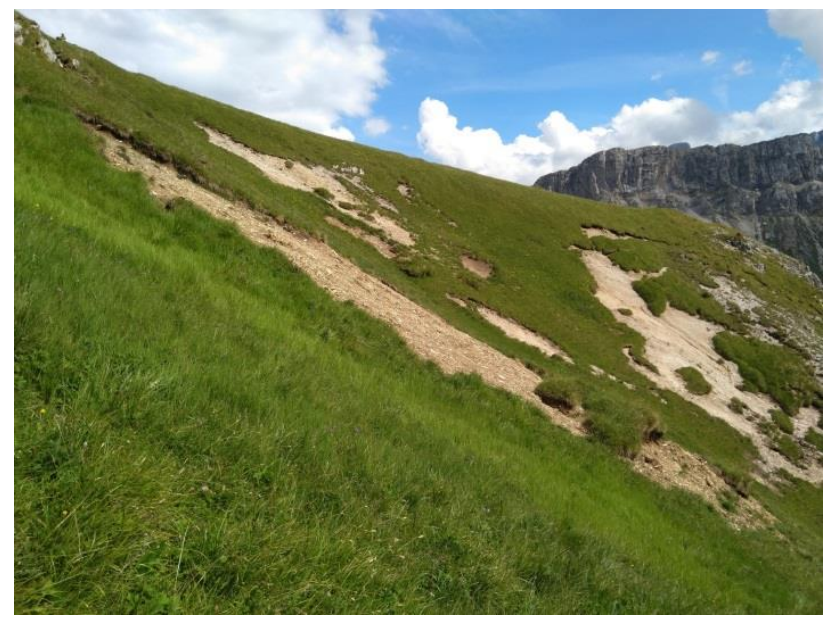

Figure 1. Example for shallow eroded areas at the test site in the Dolomites (South Tyrol, Italy).

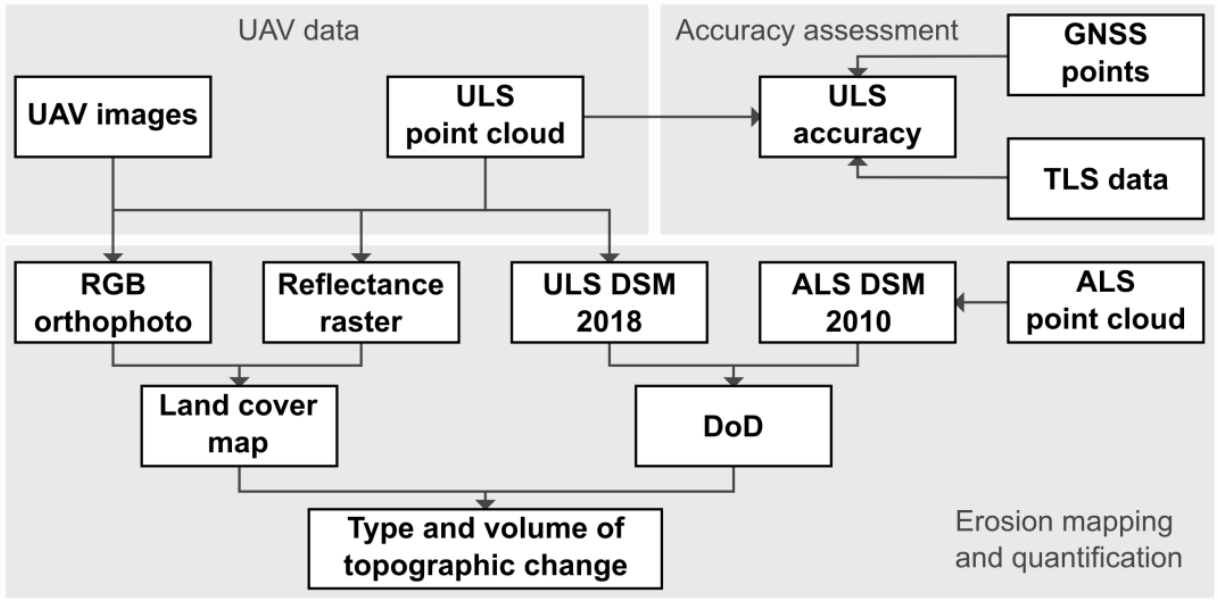

Figure 2. Schematic overview of the study concept.

\section{TEST SITE}

The test site covers 48 ha of the Dolomites and is located in the Villnöß Valley (South Tyrol, Italy), with elevations ranging between 2110 and $2470 \mathrm{~m}$ a.s.l.. Parts of the test site are used as cattle pasture, while other parts are fallow meadows and pastures. Only a minor part is still mown today. A few trees and shrubs are scattered over some sections in the lower and central part. In some locations rock crags as well as a couple of boulders and debris from rock fall complement the morphological diversity of this typical subalpine/alpine site.
Multi-temporal aerial orthophotos indicate the development of several new eroded areas during the last ten years. Field observations in spring and early summer 2018 pointed to snow gliding processes and full-depth avalanches, tearing and scraping off the grass cover together with the root layer and soil, as the dominant mechanism for shallow erosion in most parts of the test site. 


\section{METHODS}

\subsection{Data acquisition and pre-processing}

3.1.1 ULS: ULS data was acquired with a Riegl RiCopter, an octocopter with a payload of $16 \mathrm{~kg}$ and a maximum take-off mass of $24.9 \mathrm{~kg}$. This carrier platform is equipped with a Riegl VUX-1LR laser scanner (Riegl LMS, 2019), combined with an Applanix AP20 (Applanix, 2019) inertial measurement unit (IMU) and GNSS receiver as well as two calibrated oblique Sony Alpha 6000 cameras.

The VUX-1LR long range scanner is a lightweight scanner with a measurement accuracy of $15 \mathrm{~mm}$. It works with a rotating mirror, deflecting the laser light orthogonally to the longitudinal axis of the device and allows a field of view (FOV) of $330^{\circ}$. It works in the near-infrared domain $(1550 \mathrm{~nm})$ and has a beam divergence of $0.5 \mathrm{mrad}$. The AP20 IMU/GNSS recorded sensor position and orientation during flight in order to derive flight trajectories, which are used for point cloud extraction. Due to the terrain complexity a detailed flight planning, graded in different height levels was made with the software UgCS (SPH Engineering, 2019). The flights were conducted with an average flying height of $70 \mathrm{~m}$, a pulse repetition rate (PRR) of $820 \mathrm{kHz}$, an angular scan resolution of $0.0496^{\circ}$ and a flight speed of $8 \mathrm{~m} / \mathrm{s}$. The camera acquisition interval was set to $1.5 \mathrm{~s}$.

IMU/GNSS data was differentially corrected with the software POSPac (Applanix, 2019) using the permanent base station Sterzing/Vipiteno of the South Tyrolean Positioning Service. Based on the corrected trajectories, points were extracted by offline waveform decomposition and georeferenced with the software tools RiAnalysis and ReWorld, run from the application RiProcess. Strip adjustment was done with the software RiPrecision (Riegl LMS, 2019).

The point cloud was colorized in RiProcess using the simultaneously acquired Sony Alpha 6000 images. The ULS point cloud was exported in $100 \mathrm{~m}$ by $100 \mathrm{~m}$ tiles for subsequent batch processing in SAGA GIS (Conrad et al., 2015) with the extension LIS Pro 3D (Rieg et al., 2014). After removal of isolated points, a virtual point cloud was created (i.e an XMLbased catalogue description of all tiles for tile-free access to point cloud subsets). Furthermore, all tiles were rasterized to $0.1 \mathrm{~m}$ cell size, using the interquartile (i.e. $25 \%$-trimmed) mean of an attribute for all points in a raster cell. Subsequently, the raster tiles were merged to one large raster per attribute. This workflow produced (i) a digital surface model (from the $\mathrm{z}$ values), (ii) a reflectance raster (from range-corrected laser intensity) and (iii) a raster for each RGB colour channel.

3.1.2 GNSS: GNSS reference measurements of characteristic points on existing furniture and infrastructure were acquired, in order to assess the absolute (georeferencing) accuracy of the ULS point cloud. A total of 22 reference points were surveyed, mainly on top of wooden fence posts, some on sitting bench corners (points 6, 7 and 20) or the lower ends of drainage culverts at a road (points 21 and 22). The measurements were acquired with a Trimble Geo7 GNSS receiver with Zephyr antenna (Trimble Inc., 2019), and differentially corrected in post-processing with data from the three closest permanent reference stations of the South Tyrolean Positioning Service, provided with one second temporal resolution. Reported vertical error estimates after correction range from $0.033 \mathrm{~m}$ to $0.051 \mathrm{~m}$ with a mean error of $0.036 \mathrm{~m}(\mathrm{sd}=0.004 \mathrm{~m})$. Horizontal error estimates are reported to range from $0.020 \mathrm{~m}$ to
$0.032 \mathrm{~m}$ with a mean error of $0.024 \mathrm{~m}(\mathrm{sd}=0.004)$.

3.1.3 TLS: The central part of the test site was surveyed with terrestrial laser scanning (Fig. 3) using a Riegl VZ-6000 scanner (Riegl Measurement Systems GmbH, 2018). To reduce occlusions, two scans from different positions were acquired, at a distance of approximately 200 to $350 \mathrm{~m}$ from the investigated slope section. The TLS point clouds were exported from RiScan Pro (Riegl Laser Measurement Systems GmbH, 2018) to continue the processing in SAGA GIS (Conrad et al., 2015) with the extension LIS Pro 3D (Rieg et al., 2014). The two positions were coarsely georeferenced using four targets, surveyed by GNSS (global navigation satellite system). Their co-registration was refined by iterative closest point adjustment (ICP; Besl and McKay, 1992). The two point clouds were merged to one point cloud and this one was registered to the overlapping part of the ULS point cloud by ICP adjustment.

3.1.4 ALS: An unclassified ALS point cloud, acquired in 2010, is provided by the Autonomous Province of Bozen South Tyrol (2018). This ALS point cloud was registered to a downsampled copy of the ULS point cloud by ICP adjustment (Besl and McKay, 1992) and then rasterized to a DSM with $0.1 \mathrm{~m}$ cell size using the interquartile mean of the points' $\mathrm{z}$ values in each raster cell. Gaps were filled with a stepwise resampling (bilinear interpolation, grow factor $=2$ ). The ALS point cloud contains a distinct stripe pattern of both point density and elevation values, which is transferred to the ALS DSM. This pattern of relative local elevation differences was mitigated partly by application of a Gaussian filter (kernel radius $=10$ cells, $\mathrm{sd}=5 \mathrm{~m}$ ) to the ALS DSM.

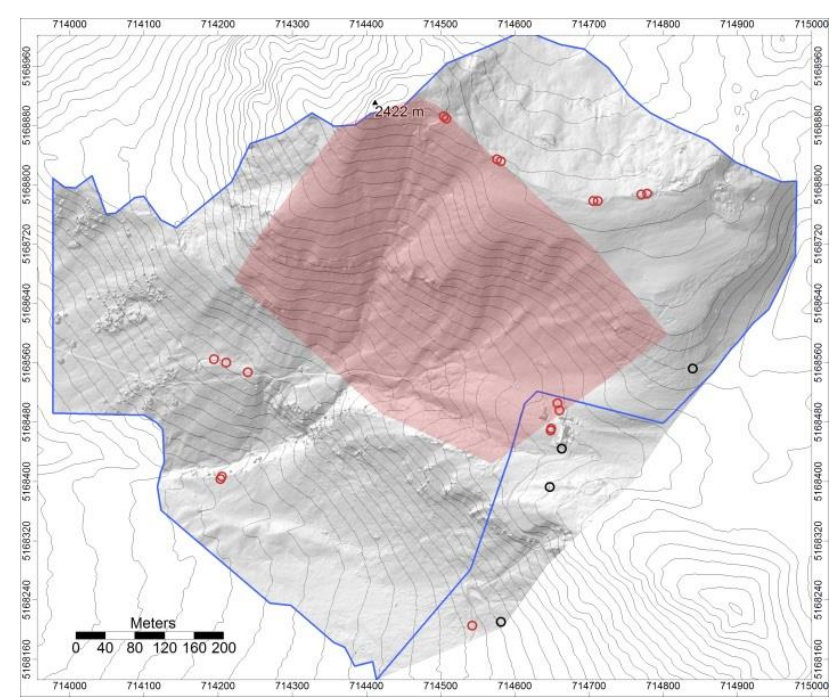

Figure 3. Test site overview and spatial coverage of the data sets. Shaded relief map: ULS data. Blue polygon: Coverage of ULS data used for change analysis. Light red: Convex hull of the TLS data. Red circles: Reference GNSS points used for georeferencing. Black circles: GNSS points excluded from georeferencing (points $18-21$ ).

\subsection{Accuracy assessment for the ULS point cloud}

The absolute (georeferencing) accuracy of the ULS point cloud is assessed by a comparison with the 22 GNSS reference points. For a $1 \mathrm{~m}$ buffer around each reference point, a point cloud subset was extracted from the virtual ULS point cloud and 
loaded into a 3D viewer. For each reference point, the corresponding ULS points were manually labelled (e.g. a group of points interpreted as the top of a fence post). The centroids of these labelled point groups were defined as ULS target points. They were compared to the GNSS target points by calculating their distances (to the closest point).

In order to improve the georeferencing, a target matching of the ULS target points to the GNSS target points was performed. This was accomplished by deriving a transformation matrix from homologous point pairs (Horn, 1987) and applying the transformation to the ULS target points. Subsequently the distances between ULS and GNSS points were recalculated.

Four points still showed comparatively large errors after target matching (Sect. 4.1), and apparently their errors could not be minimized with a rigid transformation. Hence, these points were excluded in a second run of target matching to prevent them from compromising the entire registration and, finally, distances were recalculated again.

\subsection{Mapping and volumetric quantification of shallow erosion}

The ALS DSM is subtracted from the ULS DSM to calculate a DSM-of-Difference (DoD), which represents elevation changes for the period 2010 to 2018. Horizontal registration errors produce large errors for elevation difference in steep areas. Moreover, comparatively low point densities of the ALS point cloud can strongly compromise the accuracy of the DoD in steep terrain (Sailer et al., 2013). Therefore, areas with a slope gradient $>50^{\circ}$ (including a $1 \mathrm{~m}$ buffer zone) are masked from the DoD. These areas usually lack a continuous soil and grass cover and thus are irrelevant for soil erosion monitoring in our case.

The requirement for this proof-of-concept for eroded area mapping with combined ULS/ALS is defined as the detection of elevation differences larger than $0.30 \mathrm{~m}$ in order to identify new eroded areas. In this context, Wiegand and Geitner (2013) report a mean depth of eroded areas of $0.21 \mathrm{~m}$ (measured at the scarp, excluding the vegetation height) for all their study areas in North Tyrol (Austria), while maximum depths tend to be higher. Since our DEMs are not assumed to represent the true ground but rather contain at least some of the vegetation (in undisturbed grassland), we account for this with a threshold of $0.30 \mathrm{~m}$. Only elevation differences with a magnitude larger than this threshold are analysed in the subsequent steps, even if the theoretical level of detection would be better.

The remaining DoD cells were vectorised to contiguous change objects. Subsequently, change objects with an area $\leq 2 \mathrm{~m}^{2}$ were removed, since these contained many false positives (mostly due to ALS DSM artefacts) and are negligible for monitoring this type of erosion (c.f. Wiegand et al., 2013). Volumetric changes per change object were aggregated from the DoD.

In the next step, a land cover map was created by a pixel-based Random Forest (RF) classification (Breiman, 2001), taking the RGB colour channels of the UAV-based orthophoto and the laser reflectance raster as input features. Reference areas were digitized and labelled for the target classes bare earth, grassland and trees (including shrubs) by a visual interpretation of the input feature maps. The raster cells of the training areas were randomly split into training and validation sets (70/30 split, stratified by classes). Subsequently, we aggregated the land cover class to the change objects by the majority vote of land cover cells inside each change object. Finally, we defined specific types of change as unique combinations of elevation/volumetric change direction (gain vs. loss) and land cover class and assigned these change types to every object.

A relatively small marginal part of the ULS surveyed area was completely excluded from this analysis, since it (i) suffers from georeferencing problems (Section 4.1) and (ii) contains almost no shallow eroded areas but buildings, parking cars etc. which would complicate the automated interpretation of the differential DSM and spectral data. Moreover, a few large change objects related to a larger landslide as well as conducted repairs and stabilisation measures at this landslide were deleted manually. This was necessary to derive unbiased summary statistics (Sect. 4.2).

\section{RESULTS AND DISCUSSION}

\subsection{Accuracy assessment for the ULS point cloud}

4.1.1 Direct georeferencing: The 3D mean absolute error $\left(\mathrm{MAE}_{3 \mathrm{D}}\right)$ of the directly-georeferenced ULS point cloud, calculated from all 22 reference points, is $0.213 \mathrm{~m}$. At points 18 - 21 the deviations differ considerably from the rest. Point 18 differs from points 19 - 21. If these points are excluded the $\mathrm{MAE}_{3 \mathrm{D}}$ is reduced to $0.190 \mathrm{~m}$. Excluding these four reference points, the direct georeferencing of the ULS point cloud is comparatively accurate in terms of horizontal alignment to the GNSS reference measurements, with a mean absolute error $\mathrm{MAE}_{\mathrm{xy}}=0.023 \mathrm{~m}$. In vertical direction, however, there is an offset with the ULS point cloud being consistently higher than the reference $\left(\mathrm{MAE}_{\mathrm{z}}=0.188 \mathrm{~m}\right)$.

4.1.2 Target matching (indirect georeferencing): Target matching using all reference points reduced the overall deviations from the reference points, but for points $18-21$ the deviations remain relatively high $(>0.24 \mathrm{~m})$. Thus, these points are either inaccurately measured with GNSS, or inaccurately marked in the point cloud (likely for point 21 , which was difficult to identify) or (more likely for points 18 - 20) the respective parts of the point cloud are less well georeferenced. Georeferencing problems in this marginal part of the test site can be related to the end/start of flight strips, where the UAV is decelerating to turn and tends to become instable, especially in windy conditions. This should be considered for flight planning of future missions. As they could negatively impact the entire geo-referencing, these points are excluded from the target matching. The majority of their surroundings was excluded from the erosion mapping and quantification as well (Sect. 3.3).

For the remaining points ( $1-17$ and 22), the $\mathrm{MAE}_{3 \mathrm{D}}$ is $0.041 \mathrm{~m}$ after target matching (with individual point deviations ranging from $\min =0.021$ to $\max =0.071 \mathrm{~m}$ ). This is relatively good, considering that it contains the errors from (i) GNSS measurements, (ii) manual labelling of targets, (iii) placement of the GNSS antenna on the targets, (iv) the point density and (v) ULS point measurement accuracy. Due to a lack of additional reference points, the accuracy of the point cloud is unknown for some parts of the study area. Here, a comparison with a repeated acquisition over stable (and unvegetated) areas would be interesting. 
4.1.3 Comparison with TLS data: After co-registration of the ULS and the TLS point clouds, their mean distance is $0.045 \mathrm{~m}$ (with a standard deviation of $0.045 \mathrm{~m}$ ) and the rootmean-square error (RMSE) is $0.044 \mathrm{~m}$. A DSM-of-Difference (DoD; Fig. 4) is calculated from the two point clouds and this $\mathrm{DoD}$ is analysed at representative sample areas for (i) bare earth and (ii) grassland, all in the central part of the test site (Fig. 5). The resulting mean elevation differences suggest that the two DSMs agree well in bare earth areas $(0.002 \mathrm{~m}$, sd $=$ $0.022 \mathrm{~m})$, whereas in nearby grassland areas $(-0.015 \mathrm{~m}$, $\mathrm{sd}=$ $0.047 \mathrm{~m}$ ) the TLS DSM tends to be slightly higher than the ULS DSM and the variability of elevation differences is larger. The spatial pattern of the entire DoD (Fig. 4) indicates no remarkable internal deformations, but it suggests an effect of scan angle and range, two parameters with more variation in the TLS data than in the ULS data. Partly, the DoD also seems to reflect the spatial pattern of grassland vegetation observed in the field (with different species composition and height). Moreover, differences in sensors and signal processing (e.g. regarding multi-echo detection) can account for differences. Hence, future studies could investigate the impact of different scan angles and ranges for ULS and TLS sensors systematically, in particular with regard to penetration of the grass canopy.

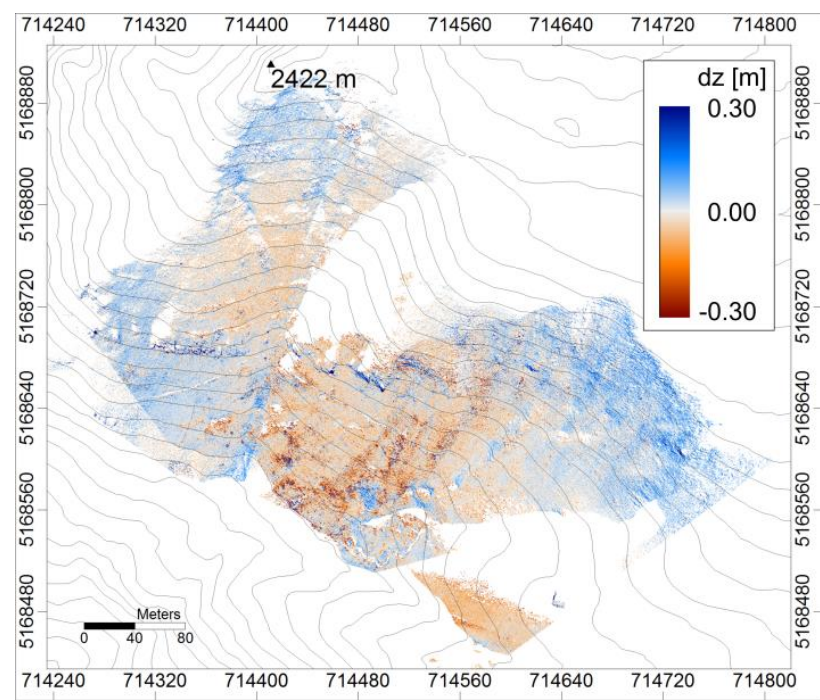

Figure 4. Raster elevation difference between the ULS DSM and the TLS DSM after fine registration; 10-m contours in grey.

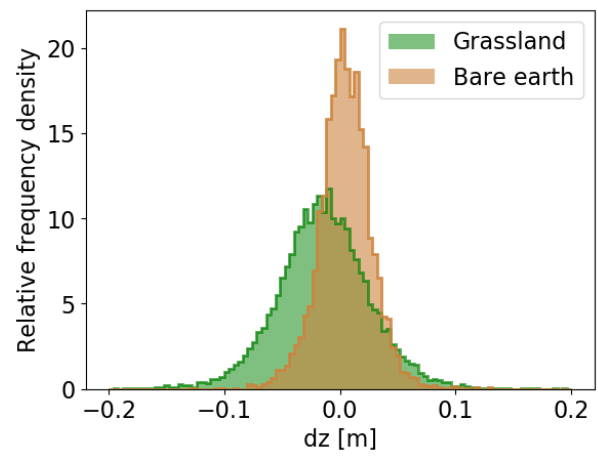

Figure 5. Relative frequency density of elevation differences (dz) between the ULS DSM and the TLS DSM for grassland and bare earth samples.

\subsection{Mapping and volumetric quantification of shallow erosion}

The combination of elevation change detection and land cover classification mapped a total of 127 (spatially contiguous) eroded area objects (see Fig. 6 for an example), with calculated volumetric changes per object ranging from $-87.6 \mathrm{~m}^{3}$ to $-0.7 \mathrm{~m}^{3}$, with a mean of $-5.3 \mathrm{~m}^{3}\left(\mathrm{sd}=9.55 \mathrm{~m}^{3}\right)$. Tab. 1 shows the total volume of different change types, while more statistics for the calculated volumes per object are presented in Fig. 7. A large portion of the total volumetric loss is attributed to the removal of trees. This phenomenon may partly result from human activity (clearing of the grassland from individual trees and shrubs). Interpretation of multi-temporal orthophotos, however, points to several cases, where a removal of trees by avalanches is more likely. None of the objects with volumetric loss were classified as trees (Tab. 1, Fig. 7), which is plausible. Note that the slope mask calculated from the ULS DSM (intentionally) removed most of the trees existing in 2018 from the analysis, with only some very small ones remaining. Type 3 changes (vegetation growth) typically refer to these cases.

\begin{tabular}{ccccc}
$\begin{array}{c}\text { Change } \\
\text { type }\end{array}$ & $\begin{array}{c}\text { Change } \\
\text { type ID }\end{array}$ & Gain/Loss & $\begin{array}{c}\text { Land } \\
\text { clover } \\
\text { class }\end{array}$ & $\begin{array}{c}\text { Total } \\
\text { volumetric } \\
\text { change } \\
{\left[m^{3}\right]}\end{array}$ \\
\hline $\begin{array}{c}\text { Vegetation } \\
\text { growth }\end{array}$ & 3 & Gain & Trees & 16 \\
\hline Deposition & 2 & Gain & Grassland & 189 \\
\hline Deposition & 1 & Gain & Bare earth & 15 \\
\hline Erosion & -1 & Loss & Bare earth & -672 \\
\hline $\begin{array}{c}\text { Removal } \\
\text { of trees }\end{array}$ & -2 & Loss & Grassland & -631 \\
\hline NA & -3 & Loss & Trees & NA
\end{tabular}

Table 1. Volumetric changes for different change types and land cover classes.

In general, the RF land cover classification with spectral features (reflectance, RGB values from imagery) performed well, with an overall accuracy of $97 \%$ (calculated from the validation set). Trees misclassified as grassland, however, reduce the precision for trees to $60 \%$, and grassland cells misclassified as bare earth are reflected by a comparatively low recall for bare earth (Tab. 2). In future studies, both the reliability and interpretability of such a validation and the accuracy of the classification results could be improved by increasing the amount of reference data.

\begin{tabular}{ccc} 
Land cover class & $\begin{array}{c}\text { Producer Accuracy } \\
\text { (Precision) }\end{array}$ & $\begin{array}{c}\text { User Accuracy } \\
\text { (Recall) }\end{array}$ \\
\hline Bare earth & 0.973 & 0.828 \\
\hline Grassland & 0.988 & 0.983 \\
\hline Trees & 0.602 & 0.997
\end{tabular}

Table 2. Accuracy metrics for the RF land cover classification. 


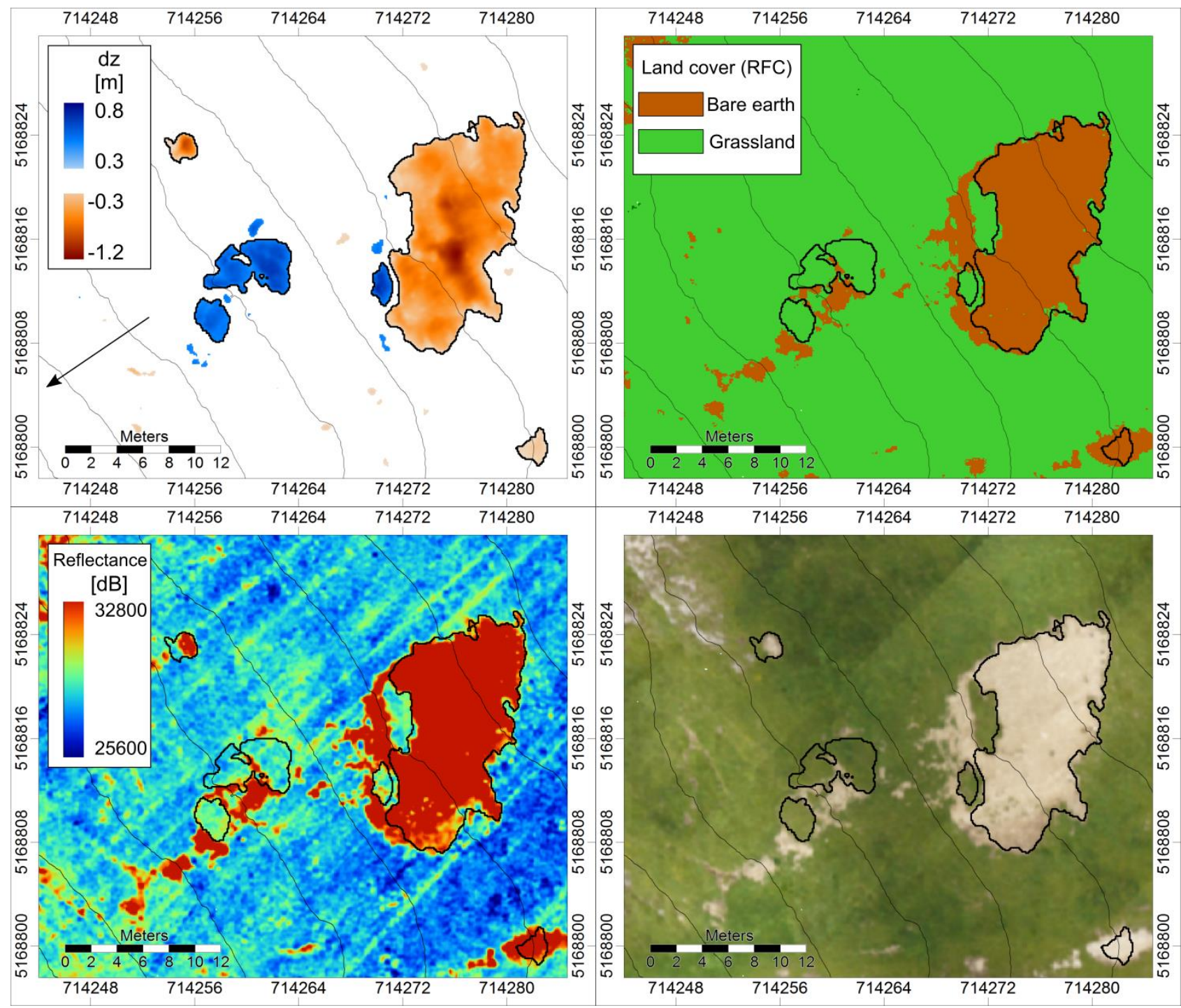

Figure 6. Example of change objects mapping with (clockwise from upper left) (i) elevation change between 2010 and 2018, (ii) Random Forest classification (RFC; no trees in this subset), (iii) RGB orthoimage, (iv) reflectance. Change objects (|dz $\mid>0.3 \mathrm{~m}$ ) are outlined by black polygons. Contour equidistance is $5 \mathrm{~m}$.

Calculated volumes for erosion (a total of $672 \mathrm{~m}^{3}$ ) can be considered as minimum values. The threshold for elevation change results in an underestimation of eroded areas in the delineation step, because bare earth areas with smaller elevation changes by erosion are disregarded. Furthermore, local/regional authorities and farmers have repaired selected eroded areas with varying success, thus precluding the detection and correct quantification of erosion in these cases. This concerns the quantification of deposits even more, because material is often deposited to meadows at the foot slopes, where farmers usually remove them. Moreover, deposits are often dispersed on a larger area, thus resulting in smaller elevation change, and are excluded by the relatively high elevation change threshold. Some eroded areas might be underestimated likewise due to errors of omission for some raster cells (mostly in transitional areas at the border of eroded areas). Taking smaller changes into account, though, would introduce a lot of false positives due to (i) ALS DEM artefacts, (ii) changes of the actual grass height or (iii) the capability of different laser scanning systems to penetrate or record vegetation.
Systematic registration errors between the ALS and the ULS data were minimized by ICP adjustment, as confirmed by a visualization of the grid differences. The point cloud RMSE, however, remained relatively high at $0.150 \mathrm{~m}$. The ALS point cloud contains a distinct stripe pattern of both point density and elevation values, and this pattern is reflected by the differential DSM as well as the shaded relief of the ALS DSM. Thus, the quality of the ALS data is rated as the main limitation for the detection of geomorphological changes. Nevertheless, the plausibility of the mapped erosion and deposition is confirmed by geomorphological interpretation and documentation in the field.

When multi-temporal data is acquired by repeat ULS campaigns, the level of detection will improve and probably make the detection of secondary erosion possible. This will, however, require a robust method to separate elevation changes by secondary erosion from changes of the grass height, for instance, which often have the same magnitude. As the presented classification of change objects shows, spectral features can be used to support this task. Alternatively or complementarily, geometric 
features could be exploited to distinguish various natural objects in an automated time series analysis (Mayr et al., 2017).

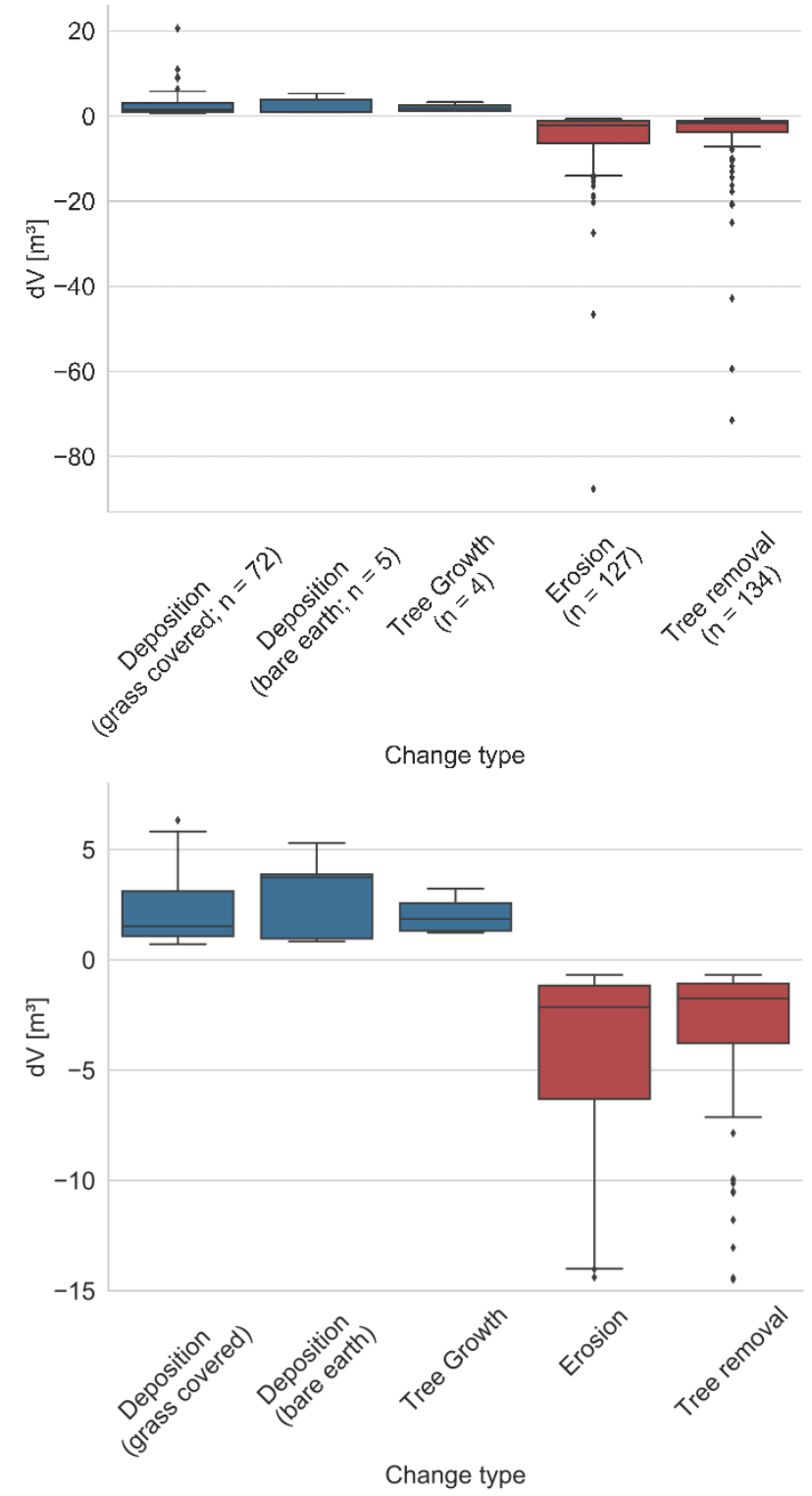

Figure 7. Changed volume (dV) per object for different types of change. Top: Full range of changes per object, including extreme values. Bottom: Changes per object only in the range between $-15 \mathrm{~m}^{3}$ and $8 \mathrm{~m}^{3}$ (i.e. different $\mathrm{y}$-axis scale).

\section{CONCLUSIONS}

With this contribution we evaluate the potential of unmanned aerial vehicle laser scanning (ULS) to monitor shallow erosion in Alpine grassland. In an accuracy assessment using differential GNSS points as a reference, the 3D mean absolute deviation (MAE3D) of our directly-georeferenced ULS point cloud is $0.190 \mathrm{~m}$. This deviation was reduced to $0.041 \mathrm{~m}$ by a targetbased registration. Comparison with TLS data confirms a similar level of accuracy for the ULS data in terms of geometric stability and noise. As a proof-of-concept for erosion quantification, we calculated the elevation difference between the ULS DSM from 2018 and an ALS DSM from 2010. For contiguous areas of elevation change the volumetric difference was calcu- lated and a land cover class, derived from the LiDAR reflectance and RGB colour, was assigned to each change object to aid the interpretation of geometric changes. This yields a total eroded volume of $672 \mathrm{~m}^{3}$ for the test site (48 ha). Such volumetric estimates of shallow erosion over multiple years are a key information for improving sustainable soil management. Based on this proof-of-concept and the accuracy analysis, we conclude that repeated ULS campaigns are well suited for erosion monitoring in Alpine grassland.

\section{ACKNOWLEDGEMENTS}

This work was funded by the Autonomous Province of Bozen South Tyrol (project ERODYN). The unmanned aerial vehicle laser scanning data has been acquired by the 4D LiDAR mountAin Monitoring laB (https://4dlamb.mountainresearch.at/) funded by the Federal Ministry of Education, Science and Research, Republic of Austria. We thank Charlotte Gild for her field work support during the UAV mission.

\section{REFERENCES}

Alewell, C., Egli, M., \& Meusburger, K. (2015). An attempt to estimate tolerable soil erosion rates by matching soil formation with denudation in Alpine grasslands. Journal of Soils and Sediments, 15(6), 1383-1399.

Applanix (2019): https://www.applanix.com/ (16 January 2019)

Autonomous Province of Bozen - South Tyrol (2018).

http://geokatalog.buergernetz.bz.it (05 July 2018)

Baltsavias, E. P., Favey, E., Bauder, A., Bosch, H., \& Pateraki, M. (2001). Digital surface modelling by airborne laser scanning and digital photogrammetry for glacier monitoring. The Photogrammetric Record, 17(98), 243-273.

Besl, P. J. and McKay, N. D., (1992). A method for registration of 3-D shapes. IEEE Transactions on Pattern Analysis and Machine Intelligence, 14(2), 239-256.

Brede, B., Lau, A., Bartholomeus, H. M., \& Kooistra, L. (2017). Comparing RIEGL RiCOPTER UAV LiDAR derived canopy height and DBH with terrestrial LiDAR. Sensors, 17(10), 2371.

Breiman, L. (2001). Random forests. Machine Learning, 45(1), 5-32.

Conrad, O., Bechtel, B., Bock, M., Dietrich, H., Fischer, E., Gerlitz, L., Wehberg, J., Wichmann, V. and Böhner, J., (2015). System for automated geoscientific analyses (SAGA) v. 2.1.4. Geoscientific Model Development, 8(7), 1991-2007.

CIPRA - Commission Internationale pour la Protection des Alpes, (2005). Protocol on the implementation of the Alpine Convention of 1991 in the field of soil conservation. Official Journal of the European Union, 337/29.

Eltner, A., Kaiser, A., Castillo, C., Rock, G., Neugirg, F., \& Abellán, A. (2016). Image-based surface reconstruction in geomorphometry - merits, limits and developments. Earth Surface Dynamics, 4(2), 359-389. 
Fey, C., \& Wichmann, V. (2017). Long-range terrestrial laser scanning for geomorphological change detection in alpine terrain - handling uncertainties. Earth Surface Processes and Landforms, 42, 789-802.

Heritage, G., \& Large, A. (Eds.). (2009). Laser scanning for the environmental sciences. John Wiley \& Sons.

Höfle, B., Geist, T., Rutzinger, M., \& Pfeifer, N. (2007). Glacier surface segmentation using airborne laser scanning point cloud and intensity data. Int. Arch. Photogramm. Remote Sens. Spatial Inf. Sci., 36(Part 3), W52, 195-200.

Horn, B.K.P. (1987): Closed-form solution of absolute orientation using unit quaternions. Journal of the Optical Society of America, A4, 629-642.

Jaboyedoff, M., Oppikofer, T., Abellán, A., Derron, M. H., Loye, A., Metzger, R., \& Pedrazzini, A. (2012). Use of LIDAR in landslide investigations: a review. Nat. Hazards, 61(1), 5-28.

Lague, D., Brodu, N., \& Leroux, J. (2013). Accurate 3D comparison of complex topography with terrestrial laser scanner: Application to the Rangitikei canyon (NZ). ISPRS Journal of Photogrammetry and Remote Sensing, 82, 10-26.

Ma, H. R., Cheng, X., Chen, L., Zhang, H., \& Xiong, H. (2016). Automatic identification of shallow landslides based on Worldview2 remote sensing images. Journal of Applied Remote Sensing, 10(1), 016008.

Mayr, A., Rutzinger, M., Bremer, M. \& Geitner, C. (2016). Mapping eroded areas on mountain grassland with terrestrial photogrammetry and object-based image analysis. ISPRS Annals of the Photogrammetry, Remote Sensing and Spatial Information Sciences, III-5, 137-144.

Mayr, A., Rutzinger, M., Bremer, M., Oude Elberink, S., Stumpf, F., \& Geitner, C. (2017). Object-based classification of terrestrial laser scanning point clouds for landslide monitoring. The Photogrammetric Record, 32(160), 377-397.

Riegl Laser Measurement Systems GmbH (2019): www.riegl.com (16 January 2019)

Rieg, L., Wichmann, V., Rutzinger, M., Sailer, R., Geist, T., \& Stötter, J. (2014). Data infrastructure for multitemporal airborne LiDAR point cloud analysis - Examples from physical geography in high mountain environments. Computers, Environment and Urban Systems, 45, 137-146.

Sailer, R., Bollmann, E., Hoinkes, S., Rieg, L., Sproß, M., \& Stötter, J. (2012). Quantification of geomorphodynamics in glaciated and recently deglaciated terrain based on airborne laser scanning data. Geografiska Annaler: Series A, Physical Geography, 94(1), 17-32.

Scaioni, M., Feng, T., Lu, P., Qiao, G., Tong, X., Li, R., Barazzetti, L., Previtali, M. \& Roncella, R. (2015). Close-range photogrammetric techniques for deformation measurement: Applications to landslides. In: Scaioni, M. (Ed.). Modern technologies for landslide monitoring and prediction (pp. 13-41).

Shan, J., \& Toth, C. K. (2018). Topographic Laser Ranging and Scanning: Principles and Processing. CRC Press.
Smith, M. W., \& Vericat, D. (2015). From experimental plots to experimental landscapes: topography, erosion and deposition in sub-humid badlands from structure-from-motion photogrammetry. Earth Surface Processes and Landforms, 40(12), 16561671.

SPH Engineering (2019): www.ugcs.com (16 January 2019)

Stumpf, A., Malet, J. P., Allemand, P., Pierrot-Deseilligny, M., \& Skupinski, G. (2015). Ground-based multi-view photogrammetry for the monitoring of landslide deformation and erosion. Geomorphology, 231, 130-145.

Syed, S., Dare, P., \& Jones, S. (2005). Automatic classification of land cover features with high resolution imagery and lidar data: an object-oriented approach. Proceedings of SSC2005 Spatial intelligence, innovation and praxis: The national biennial Conference of the Spatial Sciences Institute, September 2005, Melbourne, 512-522.

Trimble Inc., (2019): www.trimble.com (16 January 2019)

Vericat, D., Smith, M. W., \& Brasington, J. (2014). Patterns of topographic change in sub-humid badlands determined by high resolution multi-temporal topographic surveys. Catena, 120, 164-176.

Wheaton, J. M., Brasington, J., Darby, S. E., \& Sear, D. A. (2010). Accounting for uncertainty in DEMs from repeat topographic surveys: Improved sediment budgets. Earth Surface Processes and Landforms, 35(2), 136-156.

Wiegand, C., \& Geitner, C. (2010). Shallow erosion in grassland areas in the Alps. What we know and what we need to investigate further. In: Borsdorf et al. (Eds.). Challenges for Mountain Regions - Tackling Complexity (pp. 76-86).

Wiegand, C., \& Geitner, C. (2013). Investigations into the distribution and diversity of shallow eroded areas on steep grasslands in Tyrol (Austria). Erdkunde, 67(4), 325-343.

Wiegand, C., Rutzinger, M., Heinrich, K., \& Geitner, C. (2013). Automated extraction of shallow erosion areas based on multitemporal ortho-imagery. Remote Sensing, 5(5), 2292-2307.

Wieser, M., Mandlburger, G., Hollaus, M., Otepka, J., Glira, P., \& Pfeifer, N. (2017). A case study of UAS borne laser scanning for measurement of tree stem diameter. Remote Sensing, 9(11), 1154.

Wiesmair, M., Feilhauer, H., Magiera, A., Otte, A., \& Waldhardt, R. (2016). Estimating vegetation cover from highresolution satellite data to assess grassland degradation in the Georgian Caucasus. Mountain Research and Development, 36(1), 56-66.

Zieher, T., Perzl, F., Rössel, M., Rutzinger, M., Meißl, G., Markart, G., \& Geitner, C. (2016). A multi-annual landslide inventory for the assessment of shallow landslide susceptibility - Two test cases in Vorarlberg, Austria. Geomorphology, 259, $40-54$.

Zlinszky, A., Mücke, W., Lehner, H., Briese, C., \& Pfeifer, N. (2012). Categorizing wetland vegetation by airborne laser scanning on Lake Balaton and Kis-Balaton, Hungary. Remote Sensing, 4(6), 1617-1650. 